\title{
LA CUESTIÓN CONSTITUCIONAL EN EL URUGUAY CON RELACIÓN AL MERCOSUR
}

\section{A QUESTÃO CONSTITUCIONAL NO URUGUAI COM RELAÇÃO A O MERCOSUL}

Jorge E. Fernández Reyes

Resumen: La "cuestión constitucional" de la Integración de los Estados, ha sido uno de los aspectos más interesantes de análisis por parte de la doctrina constitucionalista e internacionalista, en función de su importancia en la determinación del alcance de la participación de los Estados Partes o Miembros en un proceso o esquema de integración regional de carácter económico y comercial, Se plantean aspectos propios de la soberanía de las naciones, de la independencia de los países, etc. Este documento, pretende analizar la Constitución de la República Oriental del Uruguay en relación a la "cuestión constitucional" y la relación con el Tratado de Asunción en tanto constitutivo del MERCOSUR, y la importancia de la misma, en relación a su situación actual y su proyección futura.

Resumo: A "questão constitucional" da integração dos Estados, foi um dos aspectos mais interessantes do estudo pela doutrina constitucional e internacional, em função da sua importância na determinação do alcance de participação dos Estados Partes e Membros em um processo o esquema de integração regional económico o comercial. Neste documento se estuda a Constituição do Uruguai, a questão constitucional com o Tratado de Assunção do MERCOSUL e a importância do mesmo, com a situação atual e o seu futuro.

Palabras clave: Cuestión constitucional, Procesos, Integración, Uruguay, MERCOSUR

Palavras-chave: Questão constitucional, Processo, Integração, Uruguai, MERCOSUL

* Universidad de Montevídeo, Uruguay.

E-mail: jfreyes@bkzr.com.uy

Recibido: 10/01/2018. Aceptado: 28/02/2018. 


\section{PLANTEO DEL TEMA}

El tema planteado en el Título de este documento nos lleva a considerar el tratamiento de los Tratados Internacionales por parte del Derecho Constitucional de la República Oriental del Uruguay, y específicamente con la "integración de los Estados" en general y con mayor detenimiento respecto a la participación del Uruguay en el "Mercado Común del Sur" (MERCOSUR).

No obstante ello, corresponde destacar que el estudio planteado es objeto de análisis por parte de diversas disciplinas jurídicas además del Derecho Constitucional, dentro de las cuales se destaca el Derecho Internacional Público, el Derecho de la Integración, el Derecho interno de cada país, y asimismo el relacionamiento entre dichas ramas jurídicas.

Desde una óptica más particular, y dentro de las disciplinas jurídicas que tienen a su cargo el estudio de los temas planteados en el título de esta presentación, siguiendo a Esteva Galicchio, el ámbito de tratamiento se encuentra en un "aspecto parcial de una disciplina que ha dado en llamarse "Derecho Constitucional Internacional", con el alcance que le asignan, entre otros prestigiosos autores, Luis Favoreu y Joel Rideau, es decir, de las disposiciones incluidas en las Constituciones relativas a las relaciones internacionales y al Derecho Internacional".

En ese sentido, el citado autor expresa que el Derecho Constitucional Internacional, estuvo durante mucho tiempo circunscrito a las disposiciones relativas a la competencia de los órganos del Estado para celebrar Tratados, sin embargo las relaciones internacionales han creado la necesidad para los constituyentes de establecer las bases constitucionales de esa participación, así como proceder a adaptar ciertos procedimientos internos de decisión para facilitar la puesta en ejecución de las normas que expidan dichas organizaciones internacionales.

Sobre estos aspectos, y la situación desde la óptica dela Constitución de la República Oriental del Uruguay, es que vamos a desarrollar este trabajo, teniendo en cuenta que la labor del jurista es la de describir, analizar e interpretar una situación o realidad jurídica, que en esencia es igual para todos, pero que, fruto del análisis que se propone pueden resultar conclusiones diversas.

\section{LA CONSTITUCIÓN DEL URUGUAY}

\subsection{Aspectos generales}

Las relaciones del Uruguay con otros Estados, se rigen por dos

1 ESTEVA GALICCHIO, Eduardo. "La cuestión constitucional en los cuatro Estados Partes del MERCOSUR. Serie Congresos y Conferencias No 11, el MERCOSUR después de Ouro Preto". Revista Uruguaya de Derecho Constitucional y Político, p. 36 y ss. 
clases de normas: (i) las de Derecho Interno, y en ese sentido la referencia es a las normas constitucionales y de rango legal; y (ii) aquellas propias del Derecho Internacional.

Al respecto, y desde la óptica constitucional, las relaciones del Estado uruguayo y los demás Estados se rigen por un principio fundamental que se encuentra consagrado en los artículos 2, 4 y 82 de la Constitución de la República, según los cuales el Uruguay es "independiente de todo poder extranjero", esto es, la consagración constitucional del "principio de la soberanía" del punto de vista externo, y por lo tanto todas las obligaciones o deberes que el Estado uruguayo pueda contraer frente a otros Estados, requiere necesariamente la existencia de un Tratado o Convención Internacional que se celebre de acuerdo a las formas (aspecto formal) y a su vez que los mismos sean compatibles con las normas constitucionales (aspecto sustantivo) ${ }^{2}$.

O sea, que si bien la Constitución uruguaya afirma el principio de que la soberanía radica exclusivamente en la Nación, no puede interpretarse de forma tal que niegue la posibilidad de que la República, mediante Tratados internacionales elaborados y aprobados - formal y sustantivamente - conforme a las previsiones de la Carta Magna, cree normas de Derecho Internacional capaces de obligar al Estado uruguayo.

No corresponde ingresar al análisis de la noción de soberanía, salvo en el sentido de señalar que debe interpretarse - como lo hace la doctrina mayoritaria - en que el Estado uruguayo, en cuanto soberano, puede auto limitarse dentro de los límites formales y sustantivos que impone la Constitución de la República ${ }^{3}$.

A mayor abundamiento, y como consecuencia de lo dicho anteriormente, se puede afirmar que la soberanía del Estado no es ilimitada y absoluta en su concepción actual.

En ese sentido, al decir de Esteva Galicchio, "la noción de soberanía importa una categoría histórica y no una categoría absoluta, conforme lo explico Jellinek - el maestro del derecho constitucional clásico alemán porque - prescindiendo en este momento de sus antecedentes, desde sus orígenes en el Siglo XVI en Les six libres de la repúblique de Jean Bodin, hasta el presente, ha experimentado incuestionables mutaciones. En sus orígenes fue un concepto que tuvo por finalidad afirmar la autoridad del rey frente al Papa y los señores feudales. Pero en la actualidad se asiste a

$\overline{2 \text { Dice el artículo } 2}$ de la Constitución de la República: "Ella es y será para siempre libre e independiente de todo poder extranjero", mientras que el artículo 4 expresa: "La soberanía en toda su plenitud existe radicalmente en la Nación, a la que compete el derecho exclusivo de establecer sus leyes, del modo que más adelante se expresará" y por último el artículo 82 señala: "La Nación adopta para su Gobierno la forma democrática republicana. Su soberanía será ejercida directamente por el Cuerpo Electoral en los casos de elección, iniciativa y referéndum, e indirectamente por los Poderes representativos que establece la Constitución, todo conforme a las reglas expresas en las mismas".

3 RUIZ DIAZ LABRANO, Roberto. MERCOSUR: Integración y Derecho. Buenos Aires: Ciudad Argentina, Intercontinental Editora, 1998, p. 153 y ss. 
lo que Sagues denominó la desintegración de la soberanía, naturalmente que por vía de reformas constitucionales que aborden con realismo las relaciones de los tres géneros: ordenamientos jurídicos internos; ordenamientos jurídicos de integración y comunitarios; y ordenamiento jurídico internacional"4.

A los efectos de la ubicación del tema, podemos señalar entonces, que la creación de organizaciones internacionales destinadas a asegurar la paz y la seguridad, tanto a nivel mundial como regional, que tienen en su estructura institucional órganos cuyas decisiones son obligatorias según lo disponen los Tratados respectivos, no han generado problemas desde el ámbito constitucional, ya que se refieren a decisiones adoptadas legítimamente por un órgano previsto en un Tratado, aceptado libremente por un Estado y orientado a atender una situación internacional admitida constitucionalmente, y que no reviste incidencia en el ámbito interno.

Sin embargo, en sede de los Tratados de integración comercial y económica, la necesidad de que las "decisiones" de los órganos decisorios (que constituyen el derecho derivado) establecidos en el Tratado constitutivo (derecho originario), sean aplicables en forma directa e inmediata en materias propias del derecho interno, plantea la denominada "cuestión constitucional", vale decir, el "alcance" que se encuentra previsto en la Constitución de un Estado, para habilitar la participación de una Nación en un mecanismo de integración económico y comercial, en tanto la Carta Magna de cada Estado es al decir de MIDON la "matriz jurídica de la integración"5.

\subsection{Disposiciones constitucionales que rigen los Tratados o Convenciones que puede celebrar la República Oriental del Uruguay}

Desde el aspecto sustantivo, la normativa constitucional referida al título de este numeral se encuentra prevista en varias disposiciones de la Constitución de la República.

La primera referencia, se encuentra en el inciso primero del artículo 6 de la Constitución (incorporado en el año 1934), se establece que: "En los tratados internacionales que celebre la República propondrá la cláusula de que todas las diferencias que surjan entre las partes contratantes, serán decididas por el arbitraje u otros medios pacíficos." (el destacado es nuestro).

Por su parte, en el inciso 2 del artículo 6 de la Carta Magna se expresa: "La República procurará la integración social y económica de los

4 ESTEVA GALICCHIO, Eduardo. Op. cit. p. 39.

5 MIDON, Mario. Derecho de la Integración. Aspectos Institucionales del MERCOSUR. Buenos Aires: Rubinzal - Culzoni Editores, 1998, p. 349. 
Estados Latinoamericanos, especialmente en lo que se refiere a la defensa común de sus productos y materias primas. Asimismo, propenderá a la efectiva complementación de sus servicios públicos."

Este último inciso fue incorporado en la Constitución aprobada en el año 1967, es decir en la década que algunos autores denominaron la "década de la integración"6 y en el mismo se consagra un deber para la República ("procurará" dice el texto), sin perjuicio de que su contenido es programático, dado que no es una disposición susceptible de aplicación inmediata, ya que su propia existencia no implica el ingreso de la Nación al ámbito latinoamericano del punto de vista económico y social.

Por otra parte, y vinculado a la temática en cuestión, se encuentra el artículo 50 de la Constitución cuyo texto en forma íntegra se incorpora en la Constitución de 1967 y no registra concordancias en las Constituciones de 1830, 1918, 1834, 1942 y 1952. En dicho artículo se expresa: "El Estado orientará el comercio exterior de la República protegiendo las actividades productivas cuyo destino sea la exportación o que reemplacen bienes de importación. La Ley promoverá las inversiones destinadas a este fin y encauzará preferentemente con este destino el ahorro público".

Sin perjuicio de las dificultades interpretativas que este artículo ha traído aparejado al consagrar una suerte de "proteccionismo", hay que tener presente que su inclusión en la Carta Magna ocurre en la época en que la tendencia imperante era la aplicación de una política de "sustitución de importaciones" promovida desde la CEPAL - Comisión Económica para América Latina dependiente de NNUU - Naciones Unidas) y por lo tanto parecería advertirse una cierta incongruencia con el inciso 2 del artículo 6 de la Constitución.

A nuestro criterio, se trata de dos normas de carácter programático, que esencia son compatibles, en el sentido que la actitud que el Uruguay deberá adoptar en sus negociaciones internacionales se debe orientar a la protección de sus industrias (actividades productivas), en el marco de una estrategia de integración regional complementaria con los Estados Latinoamericanos ${ }^{7}$.

Por último, y en una visión general de las normas sustantivas vinculadas al tema presentado, se encuentra otra norma de carácter programático, que obliga al Estado a combatir por medio de la ley y de las Convenciones Internacionales, los vicios sociales, así es que el artículo 47 de la Constitución, señala en forma sucinta: "El Estado combatirá por medio de la Ley y de las Convenciones Internacionales,

6 El Prof. KORZENIAK afirmaba que la expresión “década de la integración” era demasiado optimista pues parecería más bien ser la década de la "verborragia integracionista".

$7 \mathrm{Al}$ respecto debe tenerse presente, que estamos en pleno auge de los procesos de integración regional constituidos a partir de la década del 60 del siglo pasado; y a título ilustrativo se puede mencionar a la ALALC (Alianza Latinoamericana de Libre Comercio); el Pacto Andino; el Mercado Común Centroamericano, etc. 
los vicios sociales", cuyo origen se encuentra en la Constitución del año 1934 manteniéndose hasta la actualidad.

En cuanto a la forma o procedimiento, que deben seguir las autoridades de la República en la elaboración y aprobación de los Tratados Internacionales, la Constitución dispone en el numeral 20 del artículo 168, que le corresponde al Presidente de la República, actuando con el Ministro o Ministros respectivos, o con el Consejo de Ministros: "Concluir o suscribir tratados, necesitando para ratificarlos la aprobación del Poder Legislativo".

Por su parte, el numeral 7 de la artículo 85 de la Constitución, le asigna competencias al Poder Legislativo en: "Decretar la guerra y aprobar o reprobar por mayoría absoluta de votos del total de componentes de cada Cámara, los tratados de paz, alianza, comercio y las convenciones o contratos de cualquier naturaleza que celebre el Poder Ejecutivo con potencias extranjeras".

Por ende, las etapas serían las siguientes: (a) la negociación del Tratado y firma del mismo (por parte del Poder Ejecutivo); (b) la aprobación de dicho Tratado por medio de una ley (por parte del Poder Legislativo); (c) la ratificación del Tratado (por parte del Poder Ejecutivo); y por último el canje de ratificaciones o depósito del Tratado, según surja del procedimiento establecido en el propio Tratado o del Derecho Internacional.

Válidamente, se ha planteado si toda Convención o Tratado Internacional requiere la aprobación del Parlamento, es decir si desde el texto de la norma no correspondería distinguir "los tratados de paz, alianza, comercio...", de las "convenciones o contratos de cualquier naturaleza que celebre el Poder Ejecutivo con potencias extranjeras."

Varios autores nacionales han sostenido con diversos fundamentos, que ciertos contratos o convenciones que celebre el Poder Ejecutivo, no requerirían aprobación parlamentaria, básicamente atendiendo al contenido de esa convención o contrato, y las repercusiones que dicha convención o acuerdo tiene en el Derecho (esto es, sí está regida por el Derecho Internacional Público o Privado).

En el ordenamiento jurídico uruguayo, corresponde mencionar la existencia del artículo 145 de la Ley No 15.851 de 24 de diciembre de 1986, en la medida de que se trata de una regulación legal específica vinculada a la celebración de determinados "convenios o contratos" que no requerirían aprobación legislativa, en función de determinados criterios objetos que se contemplan por parte del legislador en forma expresa.

Dice el referido artículo:

"Los convenios o contratos que el Poder Ejecutivo, los Entes Autónomos y Servicios Descentralizados celebren con gobiernos extranjeros requieren la aprobación de la Asamblea General. 
No requieren ratificación legislativa los convenios o contratos que el Poder Ejecutivo, los Entes Autónomos y Servicios Descentralizados celebren con organismos internacionales de los que el país forma parte. Respecto de los convenios o contratos que celebren los Entes Autónomos y Servicios Descentralizados, la materia del convenio o contrato deberá ser propia del giro que preceptivamente les asignen las leyes, conformes a los fines de sus actividades normales. El Poder Ejecutivo establecerá los casos que requerirán su autorización previa.

En todo caso, se dará cuenta a la Asamblea General dentro de los 10 días siguientes al de su celebración".

La doctrina nacional ha ingresado tenuemente al análisis de la citada disposición legal y específicamente al inciso segundo, y sin perjuicio de otras autorizadas opiniones, a nuestro juicio encuadraría dentro de la distribución del poder de "negociar - acordar - obligar" al Estado entre el Poder Legislativo y el Poder Ejecutivo ("treaty making power), no obstante lo cual se encontraría sometido al cumplimiento de los requisitos objetivos (de carácter formal y sustantivo) que no sería aplicable al tema planteado en esta presentación (acuerdos simplificados o executive agreement).

Por último, del punto de vista constitucional, el inciso final del artículo 185 de la Constitución, recoge aspectos sustantivos y formales vinculados a los Entes Autónomos y Servicios Descentralizados del dominio comercial e industrial del Estado y su relacionamiento internacional.

Al respecto, dice el inciso final aludido: "En la concertación de convenios entre los Consejos o Directorios con Organismos Internacionales, Instituciones o Gobiernos extranjeros, el Poder Ejecutivo señalará los casos que requerirán su aprobación previa, sin perjuicio de las facultades que correspondan al Poder Ejecutivo, de acuerdo a lo establecido en la Sección V”.

Esta disposición ha sido objeto de diversas interpretaciones acerca del alcance de la misma, y si bien reviste trascendencia en la esfera de actuación de los Entes autónomos en el Uruguay, no se relaciona con el objeto de este documento.

\subsection{Tratados Internacionales de Integración Económica y Social}

De acuerdo a lo que viene de verse, el Uruguay por expresa disposición constitucional deberá procurar la integración social y económica latinoamericana, es más aún, se refiere a la integración de los Estados Latinoamericanos y no exclusivamente de Uruguay en relación a ellos.

En ese sentido Paolillo, analizando la Asociación Latinoamericana de Libre Comercio (ALAC) creada por el Tratado de Montevideo el 
18 de febrero de 1960, afirmaba que las partes integrantes de dicho organismo internacional podían denunciar el Tratado constitutivo, esto es, declarar que no pertenecían más a esa organización internacional, pero ello - y para el caso de Uruguay en forma específica - debía tener una fundamentación expresa y válida, dado que de otra forma se estaría violando el precepto constitucional que obliga a la República a procurar la integración de los Estados Latinoamericanos ${ }^{8}$.

En un sentido similar aunque no tan categórico, BARBE PEREZ afirmaba que: "Si bien en el texto no hay nada preceptivo, es evidente que ha habido una toma de posición que permite interpretar los textos constitucionales en una forma que no sean discordantes con la solución de la integración latinoamericana".

La integración económica latinoamericana representa para el Uruguay, además de una histórica aspiración y de la asunción de reiterados compromisos internacionales, un objetivo consagrado en forma expresa en la Constitución de la República.

No obstante ello, las dificultades interpretativas se encuentran en lo que la doctrina ha denominado la "cuestión constitucional" o el "problema constitucional", según hemos referido anteriormente y se desarrolla en el numeral siguiente.

Vale decir, la idea es observar dicha "cuestión" ante la realidad del ingreso de la República Oriental del Uruguay al proceso de integración denominado "MERCOSUR", a través de la firma del documento constitutivo de dicho mecanismo de integración regional, esto es, el Tratado de Asunción y en su desarrollo a través de los distintos Protocolos Adicionales.

Dicho Tratado Marco para el desarrollo de un proceso de integración destinado a la conformación de un Mercado Común entre la República Argentina, la República Federativa del Brasil, la República del Paraguay, y la República Oriental del Uruguay, en el ámbito multilateral de comercio y a los efectos de su reconocimiento a nivel del GATT (Acuerdo General sobre Tarifas y Aranceles) utilizó el "paraguas jurídico" de la ALADI, a los efectos de la no aplicación del Principio de No Discriminación a través de la Cláusulas de la Nación Más Favorecida y la Cláusula del Trato Nacional, y ello específicamente para lo establecido en los Anexos I, II y IV de dicho Tratado.

\subsection{La "cuestión constitucional” y el Tratado de Asunción}

Las disposiciones constitucionales citadassonelmarcoinstitucional

8 PAOLILLO, Felipe. Las normas constitucionales sobre integración económica y social. Revista de la Facultad de Derecho y Ciencias Sociales, n 19, p. 197 y ss.

9 BARBE PEREZ, Héctor. Aspectos administrativos en la reforma constitucional uruguaya. Montevideo: CEN, 1967, p. 81. 
del Uruguay en que se ha iniciado el proceso de integración regional MERCOSUR, a partir de la suscripción del Tratado de Asunción y sus respectivos Protocolos adicionales o complementarios ya sea en: (i) el ámbito institucional de la ALADI y siguiendo el régimen allí establecido, así como por (ii) la aprobación de la "Normativa MERCOSUR" a través de los órganos decisorios del MERCOSUR; y (iii) por la incorporación de la normativa aprobada en el seno del MERCOSUR en los ordenamientos jurídicos de los Estados Partes ${ }^{10}$.

En la actualidad, no se discute la compatibilidad del Tratado de Asunción con el sistema constitucional uruguayo, así como con los sistemas constitucionales de los otros Estados Partes y fundadores, que recogían - en la época de aprobación del texto constitutivo del MERCOSUR -, en forma más o menos explícita la posibilidad de su incorporación al mentado esquema de integración económica y comercial en los términos y condiciones que surgían de dicho Tratado fundacional, que en sustancia contenía disposiciones que claramente demostraban su "naturaleza intergubernamental" con las derivaciones lógicas en su institucionalidad orgánica y normativa ${ }^{11}$.

Desde la Constitución de la República vigente, es pacíficamente admitido que la República Oriental del Uruguay puede participar en procesos de integración económicos y sociales de carácter intergubernamental, esto es, que supongan la creación de órganos intergubernamentales con representación de los Estados en su integración, con el corolario lógico de que las normas emanadas de dichos órganos tendrán que ser necesariamente "incorporadas" al ordenamiento jurídico nacional de los Estados Partes para que tengan aplicación en los mismos, sin perjuicio de la importancia de la vigencia simultánea.

El planteo en esencia y que deviene problemático en el análisis del devenir y la proyección futura del proceso de integración (i.e. MERCOSUR) para nuestro país, se encuentra entonces en lo que denominamos anteriormente como "cuestión constitucional", extremo

10 En el sentido indicado, la referencia es en primer lugar a los más de 100 Protocolos Adicionales al Acuerdo de Alcance Parcial No 18 de la ALADI, en segundo lugar y a vía de ejemplo al Protocolo de Ouro Preto del año 1994 sobre la Estructura Institucional del MERCOSUR, el Protocolo de Olivos; y por último todas aquellas Normas MERCOSUR que fueron incorporadas por los Estados Partes en sus respectivos ordenamientos jurídicos nacionales.

11 El Tratado de Asunción fue ratificado legislativamente por la República Argentina a través de la Ley No 23.981, del 15 de agosto de 1991 efectuándose el depósito del instrumento de ratificación 30 de octubre de 1991; por la República Federativa del Brasil por Decreto Legislativo No 197, del 25 de setiembre de 1991, promulgado por Decreto No 350, del 25 de noviembre de 1991, efectuándose el depósito del instrumento de ratificación el 30 de enero de 1991; por la República del Paraguay mediante la Ley No 9/91, del 30 de mayo de 1991, efectuándose el depósito del instrumento de ratificación el 6 de agosto de 1991; por la República Oriental del Uruguay por Ley No 16.196, de 22 de julio de 1991, efectuándose el depósito del instrumento de ratificación el 6 de agosto de 1991. 
que se aplica en el mismo sentido para la República Federativa del Brasil, mientras que - en la actualidad - no se estaría planteando a nivel constitucional en la República Argentina y en la República del Paraguay.

Vale decir, en ocasión de la suscripción del Tratado de Asunción las Constituciones de los Estados fundadores no preveían la posibilidad de ingresar o participar en mecanismos de integración de carácter supranacional o supraestatal, teniendo presente que las características de supranacionalidad se encuentran plasmadas en la institucionalidad orgánica (i.e. órganos comunitarios) y normativa (i.e. aplicación directa, inmediata y efecto directo de las normas comunitarias, esto es, emanadas de órganos comunitarios).

Dicha imposibilidad o restricción constitucional, fue superada con distinto alcance y requerimientos formales y sustantivos por las reformas constitucionales realizadas, por la República Argentina, en el año 1994 (numeral 24 del artículo 75), y por la República del Paraguay en el año 1992 (artículo 145), que en sustancia habilitan la participación de dichos Estados en esquemas de integración regionales de carácter supranacional o supraestatal.

En la República Oriental del Uruguay, y teniendo presente las disposiciones señaladas en los numerales 2.1 y 2.2 de este documento, esto es, que contemplan una escasa y ambigua regulación de la integración económica y social del Uruguay en América Latina, el tema fue objeto de un intenso y valioso debate de carácter doctrinario.

Siguiendo en este punto a Esteva Galicchio, encontramos una primera aproximación al tema, y en ese sentido afirma el citado autor: "La doctrina del Derecho Constitucional latinoamericano general entiende por cuestión constitucional la relativa a sí los tratados que instituyen organizaciones supranacionales o supraestatales en materia de integración son compatibles a incompatibles con las Constituciones vigentes en los respectivos Estados"12.

De manera similar, la conceptualiza Gros Espiell, refiriéndose a la "cuestión constitucional" como "...la compatibilidad de la Constitución con una organización internacional... estructura un sistema de órganos capaces de adoptar decisiones válidas en la materia, que obliguen al Estado y que tenga, además, una aplicabilidad inmediata, erga omnes en la esfera interna"13.

Como ya dijimos, hay coincidencia en que la Constitución uruguaya permite o habilita sin dificultades, que la República participe o forme parte de procesos o esquemas de integración que impliquen la institucionalización de una organización intergubernamental.

Al respecto, y de acuerdo a prácticamente toda la doctrina

12 ESTEVA GALICCHIO, Op. cit., p. 36.

13 GROS ESPIELL, Héctor. La integración económica de Latinoamérica y la Constitución uruguaya. Temas Jurídicos, n 1, 1968, p. 37. 
nacional que se ha ocupado del tema - con algunas excepciones - el inciso 2 del artículo 6 de la Constitución es una norma de carácter programático, de directiva o de directiva política, y como se trata de una norma programática contiene un criterio de interpretación de la Constitución, que sin lugar a dudas habilita la participación de Uruguay en procesos de integración económicos y sociales que impliquen una institucionalidad orgánica y normativa de tipo intergubernamental ${ }^{14,15}$.

Esto no significa que no existan otras posiciones doctrinarias a partir del mismo texto constitucional, es decir, que estimen que el constituyente fue más allá y habilitó la participación de la Nación en procesos de integración cuya institucionalidad orgánica y normativa incorporara aspectos comunitarios o supranacionales.

Con la finalidad de ordenar este tema, esto es, en cuanto al alcance de la disposición constitucional antes referida (i.e. inciso 2 del artículo 6 de la Carta Magna), en el marco de los procesos de integración económicos y sociales, se han planteado tres corrientes doctrinarias que han sido resumidas acertadamente por Delpiazzo en su trabajo sobre los "Alcances y Límites del Derecho de la Integración"16.

En una interpretación amplia, se ha considerado que la expresión "integración económica y social" debe considerarse abarcativa y comprensiva de "todas la formas institucionales que puede adoptar la integración, desde aquellas que se basan sobre esquemas predominantemente intergubernamentales, hasta la forma más avanzada de supranacionalidad"17.

Por su parte en una interpretación restringida, se ha estimado que dicho artículo "no autoriza la formación de "órganos extranacionales para gobernar la actuación social o económica de América Latina, es decir, no permite que el Uruguay admita la existencia de órganos latinoamericanos extranacionales que asuman competencia en materia económica o social que, de acuerdo con las disposiciones de la Constitución nacional, deben ser cumplidas por órganos del Estado uruguayo"18.

Abundando en la posición aludida, y con especial referencia al MERCOSUR (i.e. Tratado de Asunción y Protocolos complementarios), se ha dicho que no es admisible "la delegación o transferencia a órganos supranacionales creados por tratados", por lo que "para que la

\footnotetext{
14 En contra de esta posición y aceptando la posibilidad de la supranacionalidad a partir del texto constitucional, se puede ver - con una importante fundamentación - a VIEIRA, Manuel. "La integración latinoamericana". En Alcances y aplicaciones de la nueva Constitución uruguaya. Montevideo: IEPAL, 1967, p. 164.

15 Al respecto, PAOLILLO, Op. cit., p. 198-200; GROS ESPIELL, Op. cit., p. 37; FRUGONE SCHIAVONE. "Solución de controversias en el MERCOSUR". Serie Congresos y Conferencias de la Revista Uruguaya de Derecho Constitucional y Política, p. 70.

16 DELPIAZZO, Carlos. "Alcances y límites del Derecho de la Integración”. Revista de Derecho Público, no 13, 1998, p. 45 y ss.

17 VIEIRA, Manuel, Op. cit., y CORREA FREITAS, Ruben. "El MERCOSUR ante la Constitución uruguaya”. La Justicia Uruguaya, Tomo CIII, Sección Doctrina, p. 13.

18 KORZENIAK, José citado por DELPIAZZO en la obra referida en la cita número 16.
} 
institucionalización definitiva del proceso de integración se concrete en la existencia de un órgano u órganos supranacionales cuyas decisiones sean directamente aplicables a los sujetos internos de los Estados miembros será menester realizar reformas constitucionales"19.

En una tesis intermedia, Gros Espiell, ha señalado que es deber del intérprete, "proceder a una racional adaptación de la Constitución a la nueva realidad, mediante una interpretación evolutiva y lógica”20.

La interpretación antes aludida, a juicio del citado autor le permite concluir que si bien "nada impide que los órganos comunitarios adopten decisiones y que éstas sean directamente aplicables en el Uruguay...", reconoce como límites que éstas "...supongan o impliquen una situación internacional o vinculada con una relación externa o interestatal..."

Y abundando en esta posición, afirma que "... no podrán sustituir a las autoridades expresamente previstas por la Constitución en el ejercicio de competencias que se refieren estrictamente a cuestiones internas, no vinculadas con una situación internacional'"21.

En consecuencia, y dentro de esta tesis intermedia, se sostiene que del punto de vista constitucional, nada impide que las autoridades internacionales o supranacionales puedan actuar en forma directa e inmediata, frente a cuestiones relativas directa o indirectamente a la integración económica, esto es, cuestiones que por su naturaleza implican directa o indirectamente una relación internacional.

La interpretación flexible de la Constitución vigente, se fundamenta además, en la orientación del constituyente plasmada en el inciso 2 del artículo 6, en la medida que a partir de dicha disposición constitucional se admitirían todos los instrumentos jurídicos necesarios para "la integración económica y social”, al igual que una vez iniciada ésta, no podría ser obstaculizada por ningún otro órgano del Estado Parte.

No obstante ello, y por la importancia de los autores que postulan esta interpretación, bueno es señalar que el Tratado de Asunción ni sus Protocolos adicionales dotaron al proceso de integración una institucionalidad orgánica (i.e. creación de órganos supranacionales o supraestatales), o una institucionalidad normativa (i.e. normas de carácter supranacional) existiendo al decir de Duran Martínez, un embrión de supranacionalidad en el Protocolo de Brasilia (actualmente en el Protocolo de Olivos) y en la Secretaría del MERCOSUR ${ }^{22,23,24}$.

19 ESTEVA GALLICCHIO, Eduardo y FRUGONE SCHIAVONE, Héctor, citados por DELPIAZZO, en la obra referida en la cita número 16.

20 GROS ESPIELL, Héctor, citado por DELPIAZZO, en la obra referida en la cita número 11. 21 DELPIAZZO, Carlos, Op. cit., p. 47.

22 El artículo 2 del Protocolo de Ouro Preto, establece que los órganos con capacidad decisoria del MERCOSUR (Consejo del Mercado Común - CMC; Grupo Mercado Común - GMC; y Comisión de Comercio del MERCOSUR - CCM) son de naturaleza intergubernamental.

23 DURAN MARTINEZA, Augusto. "Estructura Orgánica del MERCOSUR. El MERCOSUR después de Ouro Preto". Revista Uruguaya de Derecho Constitucional y Político, 1995, p. 57.

24 FERNANDEZ REYES, Jorge. La Secretaría del MERCOSUR. Revista de Derecho del 
Por último, y a los efectos de contar con un panorama completo de la normativa vigente en esta materia objeto de análisis, y específicamente en relación al Tratado de Asunción, o para ser más exactos, en el marco del proceso de integración en que se encuentra involucrado el Uruguay, orientado a la conformación de un "Mercado Común" de carácter regional, corresponde referirnos a la existencia del Decreto No 663/985, de 27 de noviembre de 1985.

A los efectos de justificar la inclusión de este Decreto en este documento, corresponde señalar que el Tratado de Asunción si bien fue objeto de ratificación legislativa por los cuatro Estados fundadores, como decíamos anteriormente requirió del "paraguas jurídico" de la ALADI para poder exceptuarse de la aplicación del "Principio de No Discriminación" del GATT en lo que respecta a lo dispuesto en los Anexos I (Programa de Liberación Comercial), II (Régimen General de Origen) y IV (Cláusulas de Salvaguarda), dado que la ALADI ya se encontraba "exceptuada" de la aplicación del mencionado principio.

Es a partir de la aprobación del Acuerdo de Alcance Parcial Acuerdo de Complementación Económica (AAP No 18) suscrito entre los cuatros países fundadores del MERCOSUR, que se han incluido más de 100 Protocolos Adicionales al AAP No 18 que se han ido incorporando al ordenamiento jurídico nacional de Uruguay, en forma prácticamente “automática" al amparo de lo dispuesto en el Decreto referido ${ }^{25}$.

La relevancia entonces radica en que por el mecanismo previsto en el Decreto referido, el Uruguay ha viabilizado la "incorporación" al ordenamiento jurídico nacional de la normativa aprobada a través de los instrumentos de política comercial establecidos en el Tratado de Montevideo de 1980.

No obstante lo expresado anteriormente, y que si bien ese mecanismo se ha venido aplicando desde la aprobación del Decreto, desde nuestro punto de vista, es importante relativizar el alcance de dicha norma reglamentaria.

Claramente se trata de acto administrativo de carácter general, aprobado por el Poder Ejecutivo mediante el cual se dispone en su artículo 1 que: "Los compromisos internacionales suscritos en el marco jurídico de la Asociación Latinoamericana de Integración (ALADI), en materia de Acuerdos de Alcance Regional y Acuerdos de Alcance Parcial (comerciales, de complementación económica, agropecuarios, de promoción del comercio o de otras modalidades tendrán vigencia plena a partir de la fecha que se haya establecido en los respectivos protocolos", y a partir de esa premisa se faculta en el artículo 2 al Ministerio de Relaciones Exteriores a través de la Representación ante la ALADI a comunicar a

MERCOSUR, vol 3, n 4,1999, p. 74.

25 Este procedimiento ha sido utilizado por otros Estados integrantes de la ALADI a través de los instrumentos legales propios de cada una de las legislaciones de los distintos países. 
las dependencias de la Administración Pública que correspondan, los instrumentos internacionales aprobados para su aplicación.

Se trataría de una incorporación al orden jurídico interno, sin que sea necesario, otro acto jurídico en la esfera interna - según se desprende del Considerando VI del Decreto en vista - de los Acuerdos de Alcance Parcial suscritos en el marco del Tratado de Montevideo de 1980 y sus Protocolos Adicionales ${ }^{26}$.

Sin embargo, desde lo establecido en el Considerando VIII del mismo Decreto, se podría interpretar válidamente dos aspectos: (i) que la notificación realizada a través de la Representación ante ALADI a los organismos nacionales encargados de su aplicación no inhibe el "dictado de los correspondientes decretos" (sic), y (ii) que no sería válida la notificación si el contenido del acto fuera de jerarquía superior a una norma reglamentaria (i.e. decreto), es decir una norma legal o constitucional.

En base a lo expresado anteriormente, y dado que éste ha sido el mecanismo utilizado parala internación devarias normas "MERCOSUR", a través de los Protocolos Adicionales al Acuerdo de Alcance Parcial No 18 (que aprueba el Tratado de Asunción y sus Anexos), se ha planteado la posibilidad de acudir a ese mecanismo de la ALADI para internalizar la "normativa MERCOSUR" en general.

En nuestro país el temperamento descrito, ha tenido opiniones doctrinarias contradictorias.

En ese sentido, Perez Otermin se manifiesta en forma favorable en la aplicación de esta vía para su internación al derecho nacional ${ }^{27}$, mientras que la opinión contraria es sostenida por FRESNEDO de AGUIRRE, la que ha tenido una Sentencia del Tribunal de lo Contencioso Administrativo a favor de esta última posición ${ }^{28}$.

Por otra parte, Gamio ${ }^{29}$, señala que "... algunos autores sostuvieron que, al haber obtenido el Tratado de Asunción su legitimación en ALADI como Acuerdo de Complementación Económica (Acuerdo No 18), como consecuencia de ello los actos de los órganos del MERCOSUR tendrían efecto directo en los Estados miembros ${ }^{\text {"30 }}$.

26 Como fundamento de la posición sustentada si cita en el Considerando VI del Decreto, las opiniones doctrinarios de JIMENEZ DE ARECHAGA, E. Introducción al problema de las relaciones entre el Derecho Internacional y Derecho Interno; y de BLUTH, Elías. "El Uruguay y la aplicación en la esfera interna del Tratado de Montevideo". Anuario de Derecho Internacional, vol 4, no 66, 1965, p. 299 y en Suprema Corte de Justicia, Sentencia de 17 de enero de 1941.

27 PEREZ OTERMIN, Jorge. El Mercado Común desde el Sur: desde Asunción a Ouro Preto. MERCOSUR: FCU, Montevideo, 1995, página 103.

28 FRESNEDO de AGUIRRE, Cecilia. "El sistema normativo del MERCOSUR y el uso de los Acuerdos de Alcance Parcial de ALADI para regular el transporte regional". En La Integración rumbo al Siglo XXI. Edición EDUCAT, 1996, p. 458.

29 GAMIO, José. “Ordenamiento Jurídico del MERCOSUR. El MERCOSUR después de Ouro Preto". Revista Uruguaya de Derecho Constitucional y Político, 1995, p. 79 y 80.

30 Se refiere a los autores BIZZOZERO, Lincol, VAILLANT, Marcel, y VERA, Tabaré en "La 
El citado autor, se cuestiona entonces: “ $¿$ por que no inscribir tales actos (se refiere a las decisiones, resoluciones y directivas emanadas de los órganos decisorios del MERCOSUR) en ALADI como Acuerdos de Alcance Parcial en el marco del Acuerdo de Complementación Económica $N^{o} 18$. ¿ (v.g. protocolos adicionales al Acuerdo de Alcance Parcial)”.

A su juicio, "tal iniciativa habría sido de interés considerarla si los demás Estados miembros del MERCOSUR hubieran sancionado una norma similar a la que nuestro país adoptó por el Decreto $N^{\circ} 663 / 985$, de 27 de noviembre de 1985, estableciendo la aplicación inmediata en el ámbito interno, de los Acuerdos de Alcance Parcial".

Pues bien, si bien puede considerarse un tema discutible, desde nuestro punto de vista y del análisis realizado, dos aspectos parecen claros que limitan en forma ostensible la utilización de dicho mecanismo.

En primer lugar, los Estados Partes al aprobar el Tratado de Asunción en tanto documento constitutivo de un proceso de integración que tiene como objetivo la conformación de un Mercado Común, han utilizado el Acuerdo de Alcance Parcial a los efectos de lograr su compatibilidad con el Principio de No Discriminación del GATT, en aquellos aspectos vinculados con los instrumentos de política comercial, y es sobre ellos que es posible aplicar el mecanismo de incorporación previsto en el Decreto No 663/985 y solamente en esas situaciones; y en segundo lugar, el mecanismo solamente sería aplicable en el caso de normas reglamentarias y complementariamente ello no inhibe el dictado de los actos jurídicos correspondientes en el orden interno.

A mayor abundamiento y en función de lo expresado, cuando se trate de cualquier disposición incluida en una convención internacional, que invada la esfera de la "reserva de la ley" (o de rango superior al Decreto), no sería válido el mecanismo de internación de las normas por la vía señalada, dado que la modificación de éstas requiere aprobación parlamentaria (o modificación constitucional), y no es suficiente la instancia administrativa genérica.

Por otra parte, y con claridad meridiana, el Protocolo de Ouro Preto, establece en forma expresa cual es el procedimiento para la incorporación o nacionalización de las normas emanadas de los órganos decisorios del MERCOSUR (artículos 38 a 40 del citado Protocolo), y por ende - a nuestro juicio - no es válido considerar una interpretación normativa que avale una aplicación inmediata y directa de dichas normas.

Por lo tanto, la responsabilidad de "adecuar" el ordenamiento jurídico de cada Estado Parte a las normas aprobadas en el esquema de integración regional del MERCOSUR (internalizar, incorporar o nacionalizar), no solamente responde a la naturaleza intergubernamental del proceso; al contenido expreso del Tratado de Asunción y del Protocolo de Ouro Preto, sino también a la vigencia y aplicabilidad de la

construcción del MERCOSUR: diagnóstico y evaluación de lo acordado”, 1993, páginas 15 y 22. 
Convención de Viena sobre el Derecho de los Tratados (v.g. artículo 26).

\section{COROLARIO}

La "cuestión constitucional" en el Uruguay se encuentra contemplada en la Constitución de la República del año 1967, en función de una realidad propia de las características de la "integración latinoamericana" de la época de su aprobación, es decir la década del 60 del siglo pasado (i.e. incorporación del inciso segundo del artículo 6).

A nuestro criterio, en forma clara e indubitable, la misma no habilita a que el Estado uruguayo participe en "procesos de integración" o "esquemas de integración" que tengan características de "supranacionalidad o supraestatalidad", es decir, sin perjuicio de una clara orientación o vocación integracionista de la Carta Magna uruguaya, la misma responde a la naturaleza "intergubernamental" de los procesos o mecanismos de integración, independientemente de cualquier elaboración doctrinaria que en términos interpretativos se pudiera hacer del texto constitucional, la conclusión no puede ser otra, esto es, la "intergubernamentalidad" en toda su dimensión (i.e. orgánica institucional y normativa).

Vale decir, la Constitución de la República Oriental del Uruguay no autoriza o no es compatible con la participación del Uruguay en una organización internacional dotada de personería jurídica, que se estructure en base a un sistema de órganos capaces de adoptar actos decisorios válidos en el proceso de integración que obliguen al Estado, y que tengan además una aplicabilidad inmediata, erga omnes en la esfera interna ${ }^{31}$.

En ocasión de la firma del Tratado de Asunción ninguno de los Estados Partes tenían resuelta en forma expresa la "cuestión constitucional" de forma tal que su participación en un proceso de integración de carácter económico y comercial pudiera ser objeto de una definición clara en cuanto al alcance de la "profundidad" de su grado de involucramiento en un esquema de integración regional, esto es, afectar espacios de su soberanía en una organización internacional y posibilitar su ingreso en un proceso de carácter supranacional o supraestatal ${ }^{32}$.

Vale decir, en ocasión de la aprobación del Tratado de Asunción (fundacional del Mercado Común del Sur), ninguno de los Estados Partes fundadores, tenían la previsión normativa constitucional que le permitiera "ingresar" a un esquema de integración de carácter supranacional o supraestatal, extremo que en la actualidad se mantiene

31 En esta afirmación debe tenerse presente el régimen previsto por el ordenamiento jurídico nacional en el marco de la ALADI, según fue desarrollado ampliamente en este documento, 32 El MERCOSUR, como proceso de integración en que se encuentran comprometidos la República Argentina, la República Federativa de Brasil, la República del Paraguay y la República Oriental del Uruguay, desde sus orígenes hasta la actualidad, ha adoptado la intergubernamentalidad como característica propia del esquema de integración. 
con plena vigencia en el caso de la República Federativa del Brasil y de la República Oriental del Uruguay.

Pues bien, es sabido que la ausencia de la supranacionalidad o supraestatalidad en el MERCOSUR, ha tenido impacto en el proceso de incorporación de la Normativa MERCOSUR en los ordenamientos jurídicos de los Estados Partes, es decir, la aplicación de los artículos 38 a 40 del Protocolo de Ouro Preto no ha sido utilizada en tiempo y forma de acuerdo a la intención de los negociadores, aunque debe señalarse que su análisis en términos cuantitativos (normas aprobadas y normas incorporadas en los Estados Partes) no es válido para una opinión certera al respecto, ya que del punto de vista cualitativo - aún con reservas - el resultado es mas auspicioso en términos de su cumplimiento.

No obstante ello, la relevancia de la supranacionalidad orgánica y normativa de un esquema de integración siempre ha estado presente en el MERCOSUR, ya sea en el desarrollo actual del proceso, y obvio es decirlo, en su proyección futura.

Como consecuencia de lo expresado anteriormente, nuestra opinión, es ciertamente favorable a la necesidad de adecuar la Constitución actualmente vigente en el Uruguay, a los efectos de posibilitar por medio de un Tratado Internacional, la posibilidad de que la República participe en un proceso de integración que contenga órganos con capacidad jurídica propia de la "supranacionalidad o supraestatalidad", y por ende, sean capaces de crear un ordenamiento jurídico comunitario, con el alcance y las características que la doctrina especializada le ha asignado a dicha concepción jurídica.

Esto no significa que la posibilidad de hacerlo del punto de vista constitucional se transforme en una obligatoriedad, pero parece necesario abordar el tema planteado, en aras de la consonancia o concordancia entre el discurso político y la manifiesta voluntad integracionista, con la imprescindible adecuación de los instrumentos jurídicos con que se cuenta para avanzar y profundizar - en su oportunidad - cualquier instancia integracionista en la que el país esté dispuesto a participar en esos términos. MERCOSUR.

En suma, abordemos honestamente la necesidad de modificar la Constitución uruguaya, sin adoptar interpretaciones evidentemente forzadas, que se transforman en inaceptables y que solo llevan al desconocimiento del texto constitucional.

\section{REFERENCIAS BIBLIOGRÁFICAS}

ARBE PEREZ, Héctor. Aspectos administrativos en la reforma constitucional uruguaya. Montevideo: CEN, 1967.

BLUTH, Elías. "El Uruguay y la aplicación en la esfera interna del Tratado de Montevideo". Anuario de Derecho Internacional, vol 4, n 66, 
1965, p. 299.

CORREA FREITAS, Ruben. "El MERCOSUR ante la Constitución uruguaya”. La Justicia Uruguaya, Tomo CIII, Sección Doctrina, p. 13.

DELPIAZZO, Carlos. "Alcances y límites del Derecho de la Integración”. Revista de Derecho Público, no 13, 1998, p. 45.

DURAN MARTINEZA, Augusto. "Estructura Orgánica del MERCOSUR. El MERCOSUR después de Ouro Preto". Revista Uruguaya de Derecho Constitucional y Político, 1995, p. 57.

ESTEVA GALICCHIO, Eduardo. "La cuestión constitucional en los cuatro Estados Partes del MERCOSUR. Serie Congresos y Conferencias No 11, el MERCOSUR después de Ouro Preto". Revista Uruguaya de Derecho Constitucional y Político, p. 36

FERNANDEZ REYES, Jorge. La Secretaría del MERCOSUR. Revista de Derecho del MERCOSUR, vol 3, n 4, 1999, p. 74.

FRESNEDO de AGUIRRE, Cecilia. "El sistema normativo del MERCOSUR y el uso de los Acuerdos de Alcance Parcial de ALADI para regular el transporte regional". En La Integración rumbo al Siglo XXI. Edición EDUCATT, 1996.

FRUGONE SCHIAVONE. "Solución de controversias en el MERCOSUR". Serie Congresos y Conferencias de la Revista Uruguaya de Derecho Constitucional y Política, p. 70.

GAMIO, José. “Ordenamiento Jurídico del MERCOSUR.ElMERCOSUR después de Ouro Preto". Revista Uruguaya de Derecho Constitucional y Político, 1995, p. 79 y 80.

GROS ESPIELL, Héctor. La integración económica de Latinoamérica y la Constitución uruguaya. Temas Jurídicos, n 1, 1968, p. 37.

MIDON, Mario. Derecho de la Integración. Aspectos Institucionales del MERCOSUR. Buenos Aires: Rubinzal - Culzoni Editores, 1998.

PAOLILLO, Felipe. Las normas constitucionales sobre integración económica y social. Revista de la Facultad de Derecho y Ciencias Sociales, $\mathrm{n}^{\circ} 19$, p. 197.

PEREZ OTERMIN, Jorge. El Mercado Común desde el Sur: desde Asunción a Ouro Preto. MERCOSUR: FCU, Montevideo, 1995.

RUIZ DIAZ LABRANO, Roberto. MERCOSUR: Integración y Derecho. Buenos Aires: Ciudad Argentina, Intercontinental Editora, 1998. 
VIEIRA, Manuel. "La integración latinoamericana". En Alcances y aplicaciones de la nueva Constitución uruguaya. Montevideo: IEPAL, 1967, p. 164.

\section{RESUMEN BIOGRÁFICO}

Jorge E. Fernández Reyes es Profesor Titular de la Cátedra de Derecho de la Integración de la Facultad de Derecho de la Universidad de Montevideo desde el 2000 hasta la fecha, asimismo se desempeña como Director de la Maestría en Integración y Comercio Internacional en la misma facultad. Representante Alterno de Uruguay ante el Tribunal Permanente de Revisión del MERCOSUR (2017). Ex Director de la Secretaría del MERCOSUR (1997 - 1998). Ex Director General del Ministerio de Relaciones Exteriores (1995 - 1996). 